\title{
PENDAYAGUNAAN DANA ZIS PADA PROGRAM MAHASISWA CERDAS BAZNAS (BAZIS) PROVINSI DKI JAKARTA
}

\author{
Sultan Antus Nasruddin Mohammad ${ }^{1}$ dan Febriani Eka Maulida ${ }^{2}$
}

\section{Abstrak}

Penelitian ini bertujuan untuk menganalisis pengelolaan pendayagunaan ZIS untuk meningkatkan pendidikan dan menganalisis mekanisme pendayagunaan dana ZIS di BAZNAS (Bazis) Provinsi DKI Jakarta pada Program Mahasiswa Cerdas. Hasil penelitian ini menunjukkan bahwa Pendayagunaan ZIS untuk meningkatkan pendidikan di BAZNAS (Bazis) Provinsi DKI Jakarta telah dilakukan dengan baik dan optimal sesuai dengan standar pendayagunaa zakat, yaitu penyaluran diberikan kepada asnaf sabilillah khusus dalam bidang keagamaan dan dhuafa/miskin yaitu kalangan masyarakat yang kurang mampu dengan mendahulukan orang yang tidak berdaya memenuhi kebutuhan dasar terlebih dahulu lalu memberikan bantuan pada pendidikannya. Selain itu, mekanisme Pendayagunaan ZIS di BAZNAS (Bazis) Provinsi DKI Jakarta pada Program Mahasiswa Cerdas dilaksanakan dengan baik dan wajar sesuai dengan standar pendayagunaan zakat di Indonesia.

Kata Kunci: Dana ZIS, Pemberdayaan Masyarakat

\section{Abstract}

This study aims to analyze the management of the utilization of ZIS to improve education and analyze the mechanism of the utilization of ZIS funds in BAZNAS (Bazis) DKI Jakarta Province in the Smart Student Program (Program Mahasiswa Cerdas). The results of this study indicate that the Utilization of ZIS to improve education in BAZNAS (Bazis) of DKI Jakarta Province has been done well and optimally in accordance with zakat utilization standards, namely distribution is given to asnaf sabilillah specifically in the religious and poor sectors of the poor. By giving priority to people who are powerless to meet basic needs and then provide assistance to their education. In addition, the mechanism for the Utilization of ZIS in BAZNAS (Bazis) of DKI Jakarta Province in the Smart Student Program is implemented well and fairly in accordance with the zakat utilization standards in Indonesia.

Keywords: ZIS Funds, Community Empowerment

\footnotetext{
${ }^{1}$ Institut Ilmu Al Qur'an Jakarta, Email: tubagussulthan@gmail.com

${ }^{2}$ Alumni Institiut Ilmu Al Qur'an Jakarta 


\section{A. PENDAHULUAN}

\section{Latar Belakang}

Pemberdayaan masyarakat berbasis zakat adalah salah satu metode pendayagunaan dana zakat yang bertujuan utamanya untuk memperbaiki kualitas hidup fakir miskin melalui pendayagunaan sumber-sumber yang ada pada mereka serta menekankan prinsipprinsip partisipasi. Dalam pendayagunaan, ada beberapa kegiatan yang dapat dikembangkan oleh Lembaga Amil Zakat ataupun Badan Amil Zakat. Kegiatan tersebut diantaranya yaitu pengembangan ekonomi, pembinaan sumber daya manusia (SDM), dan bantuan yang sifatnya sosial semata.

Allah SWT telah menetapkan pembagian harta zakat. Zakat milik mustahik yang jumlahnya ada delapan tidak berubah dan tidak bertambah ditegaskan dalam Al-Qur'an surat At-Taubah (9): 60.

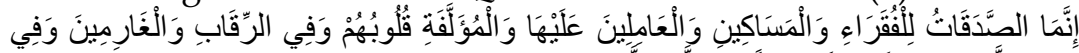

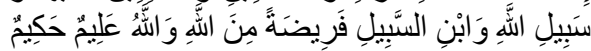

Artinya: "Sesungguhnya sedekah (zakat) itu untuk orang-orang fakir, orangorang miskin, para amil zakat (petugas zakat), para mu־allaf (yang dijinakkan hatinya), untuk memerdekakan hamba sahaya (budak), orang yang berhutang, orang yang berjuang di jalan Allah dan untuk para musafir, sebagai suatu kewajiban dari Allah, Allah Maha Mengetahui lagi Maha Bijaksana (QS. At-Taubah: 60)

Maka jelas zakat sudah ditetapkan peruntukannya, berdasarkan perintah Allah yaitu untuk delapan ashnaf. Namun, ada dua pendapat yang muncul. Pertama, menukil pendapat dasar dari imam mazhab empat (Hanafi, Maliki, Syafi' i dan Hambali) yaitu;

Pertama, Sebagaimana dalam kitab Bughyatul Mustarsyidin hlm 106 dan Al-Mizanul Kubra bab Qismu al-Shadaqah bahwa tidak diperbolehkan mengeluarkan zakat untuk lembaga sosial, bahkan untuk membangun masjid sekalipun atau untuk mengkafani (mengurus) orang mati. dinyatakan bahwa masjid itu sama sekali tidak berhak untuk menerima zakat, karena zakat itu penyalurannya tidak boleh kecuali untuk orang muslim yang merdeka. 
Kedua, para musyawirin lainnya menyatakan boleh mengalirkan dana zakat di sektor sosial yang ๑positif® seperti membangun masjid, madrasah, mengurus orang mati dan lain sebagainya.

Kelompok fakir-miskin, pendayagunaannya untuk meningkatkan kualitas sumber daya manusia dan kesejahteraan mereka. Untuk kelompok sabilillah, pendayagunaannya untuk pembinaan kegiatan keagamaan. Sedangkan pendayagunaan untuk kelompok muallaf, gharimin, dan ibnusabil diarahkan pada pembinaan akidah, pemberian bantuan pelunasan hutang bagi yang tidak mampu membayarnya, dan bantuan bagi mereka yang kehabisan bekal dalam perjalanan.

Kegiatan sosial pendidikan merupakan cara terbaik untuk meningkatkan kualitas sumber daya manusia suatu bangsa, Di Indonesia khususnya di Jakarta masalah putus sekolah telah menjadi fenomena tahunan setiap kelulusan sekolah dan saat penerimaan siswa baru dimulai. Hal ini disebabkan mahalnya biaya pendidikan yang harus di tanggung, daya serap pendidikan masih rendah dan anggaran pendidikan belum terpenuhi sebagaimana ketentuan UU yakni $20 \%$ dari APBN/APBD yang diamanatkan UU No.20 tahun 2003 yakni pasal 49 ayat 1.

Pendidikan menjadi ruang pembaharuan bagi kehidupan, karena dengan pendidikan dapat merubah keadaan menjadi lebih baik. Dalam ranah perzakatan, pendayagunaan pada bidang pendidikan merupakan kebutuhan, melihat keadaan masyarakat yang masih terpuruk, karena belum mendapatkan subsidi pendidikan bagi putra putrinya untuk melanjutkan pendidikan di tingkat yang lebih tinggi. Masalah yang dihadapi masyarakat Islam adalah tingkat kehidupan sosial mereka yang sebagian besar memang masih jauh dari garis-garis kecukupan, akibatnya banyak anak-anak mereka yang tidak dapat melanjutkan sekolah bahkan tidak sedikit yang putus sekolah.

Ada dua kategori pendayagunan ZIS di BAZNAS (Bazis) Prov. DKI Jakarta yaitu; bantuan dan santunan. Bantuan adalah dana yang diberikan oleh BAZNAS (Bazis) Prov. DKI Jakarta yang dipergunakan untuk kepentingan antara lain; sarana ibadah, sarana pendidikan Islam, beasiswa pendidikan, modal usaha bagi pedagang kecil dan lain-lain. Sedangkan santunan adalah pemberian dana untuk keperluan konsumtif, seperti untuk pembelian makanan dan pakaian bagi fakirmiskin, dan orang-orang yang ditimpa musibah. BAZNAS (Bazis) Prov. DKI Jakarta telah menjalankan program peningkatan kualitas 
pendidikan, demi menjunjung tinggi nilai-nilai pendidikan di Indonesia. Program tersebut adalah program Mahasiswa Cerdas, yang selama ini di fokuskan oleh BAZNAS (Bazis) Prov. DKI Jakarta dengan memberikan bantuan bagi masyarakat Prov. DKI Jakarta khususnya kepada anak bangsa yang cerdas dan berprestasi untuk melanjutkan pendidikan ke jenjang yang lebih tinggi, yaitu jenjang perguruan tinggi, serta memberikan bantuan-bantuan pembiayaan sekolah untuk masyarakat kalangan bawah. Program ini bertujuan untuk meningkatkan kualitas pendidikan yang menjadi salah satu tujuan agar mengurangi kebodohan dan yang akan berimbas pada perekonomian di Indonesia. Banyak anak bangsa yang memiliki kemampuan serta kecerdasan, namun dikarenakan mahalnya biaya pendidikan yang akan diambil menjadikan alasan tidak dapat melanjutkan pendidikannya. Ditinjau dari beberapa pandangan perbedaan pendapat terhadap dana ZIS untuk peningkatan pendidikan. Pendayagunaan dana ZIS sudah sesuaikah dengan tujuan dan sasaran targetnya atau belum.

\section{Pembatasan dan Perumusan Masalah}

Potensi pembiayaan melalui dana umat terutama masyarakat muslim yang dalam kehidupan kesehariannya dituntut untuk berbuat baik dan bermanfaat bagi orang lain. Pemerataan pendidikan bermakna bahwa dalam keadilan dalam memperoleh kesempatan harus berlaku bagi seluruh masyarakat, tetapi masih banyak masyarakat Indonesia yang belum mendapatkan pendidikan terutama masyarakat fakir dan miskin yang sebenarnya masuk kedalam kategori penerima zakat. Maka masalah pembiayaan pendidikan berbasis umat yang terdapat dalam perihal masalah pengelolaan zakat yang bermanfaat untuk dunia pendidikan terutama untuk meningkatkan kualitas pendidikan fakir miskin yang merupakan mustahiq zakat. Dari uraian tersebut maka pokok masalah dalam tulisan ini dapat dirumuskan sebagai berikut: (1) Bagaimana pengelolaan pendayagunaan ZIS untuk meningkatkan pendidikan yang dijalankan oleh BAZNAS (Bazis) Prov. DKI Jakarta?, dan (2) Bagaimana mekanisme pendayagunaan dana ZIS BAZNAS (Bazis) Prov. DKI Jakarta pada Program Mahasiswa Cerdas? 


\section{B. METODE PENELITIAN}

1. Metode Penelitian:

Metode penelitian ini adalah kualitatif, dimana variabel dan data yang dianalisis bersifat kualitatif. Penelitian ini juga menggunakan metode deskriptif (descriptive research) dengan pendekatan analisis. Tujuan dari penelitian deskriptif ini adalah untuk membuat deskripsi, atau gambaran secara sistematis, faktual dan akurat mengenai fakta, sifat-sifat serta hubungan antara fenomena pada objek penelitian sesuai dengan permasalahan yang diteliti, untuk kemudian dianalisis.

2. Sumber data:

Secara umum data yang digunakan dalam penelitian ini merupakan data-data primer dan sekunder. Data serta berita langsung dari hasil wawancara dan observasi kepada staff dan pengurus mengenai pendayagunaan dana ZIS yang dilakukan oleh BAZNAS (Bazis), dan kitab-kitab Figh Islam terkait dengan zakat dan sistem pendayagunaan serta referensi dari berbagai sumber lain yang berkaitan dengan pembahasan penelitian ini.

3. Teknik Pengumpulan Data:

Adapun teknik pengumpulan data yang dilakukan dalam penelitian ini adalah library research (penelitian kepustakaan). Dalam penelitian ini penulis mencari data-data, literatur-literatur dan referensi yang berkaitan dengan judul tesis serta pembahasannya. Dari penelitian ini diharapkan dapat memperoleh kerangka teori dan konsep yang dapat mendukung pokok pembahasan dalam penelitian ini.

4. Teknik Pengelolaan Data :

Semua materi dijelaskan dan dianalisa serta diletakkan secara kronologis, kemudian diuji/dianalisa korelasi dan relevansinya antara pendayagunaan ZIS yang ada dengan Fiqih Islam dan aplikasinya pada pendayagunaan zakat di BAZNAS (Bazis).

\section{PEMBAHASAN}

Pada hakikatnya zakat merupakan instrumen yang penting dalam meningkatkan ekonomi Islam serta merupakan sumber kekuatan dalam mengentaskan kemiskinan dan meningkatkan kualitas kehidupan umat manusia. Kesadaran berzakat memang menjadi tolak ukur ketaatan seseorang terhadap kewajiban atas agamanya. 


\section{Pendayagunaan ZIS BAZNAS (Bazis) Provinsi DKI Jakarta Untuk Pendidikan}

Salah satu akar permasalahan pendidikan pada umumnya adalah pembiayaan. Orang tua tidak memiliki dana cukup membiayai pendidikan anaknya karena pendapatan rendah, tidak sebanding dengan tingginya biaya pendidikan yang harus ditanggung. Karena itu tanpa peningkatan pembiayaan dari pemerintah, maka jelas pendidikan di Indonesia sangat sulit untuk keluar dari krisis. Memang UUD 1945 telah menetapkan, anggaran 20 persen, yang dipikul oleh pemerintah pusat dan daerah, tetapi kita semua mengetahui bahwa, tetap belum terjadi peningkatan yang betul-betul signifikan dalam anggaran pendidikan. Kondisi ini dapat menyebabkan negeri ini kehilangan generasi, dikarenakan yang akan datang adalah generasi yang memiliki kualitas intelektual yang rendah sehingga di khawatirkan akan menjamurnya kasus pekerja anak, anak jalanan, pelacuran anak dan kasus sosial anak lainnya akibat kemiskinan dan takanan hidup (Thoin, 2017:162).

Pendayagunan ZIS di BAZNAS (Bazis) Prov. DKI Jakarta agar berjalan dengan lancer, memberikan informasi kepada mereka dengan jaringan media-media dan sistem informasi yang dimiliki. Karena disadari atau tidak, bahwa BAZNAS (Bazis) Provinsi DKI Jakarta hanya mediator antara the haves dengan mustahik. ZIS yang ada hanya titipan bagi mereka yang mampu, dan pada saat yang sama merupakan hak bagi mereka yang kurang mampu. Ada dua proses yang dilakukan BAZNAS (Bazis) Provinsi DKI Jakarta dalam upaya pendayagunaan ini. Pertama,upaya aktif. Upaya ini dilakukan dengan mekanisme dan prosesdur yang baku. Proses ini dilakukan melalui rapat tahunan dengan melihat perkembangan peta ekonomi, sosial dan politik masyarakat yang ada. Misalnya memberikan bantuan kepada para pedagang tradisional, beasiswa pendidikan dan lain-lain. Kedua, upaya reaktif. Hal ini dilakukan pada setiap kejadian diluar kemampuan analisa kemanusiaan. Misalnya banjir, kebakaran dan lain-lain.

Masalah yang ada di tengah-tengah masyarakat adalah berkenaan dengan tingkat kehidupan sosisal yang masih rendah dibawah garis kecukupan, yang berakibat banyaknya keluarga yang tidak mampu membayar biaya pendidikan anaknya. Tidak hanya bersumber dari faktor eksternal ataupun faktor institusi dan kondisi lingkungan yang 
mempengaruhi keberhasilan anak dalam meraih prestasi, melainkan bisa disebabkan oleh faktor keluarga termasuk status sosial orang tua anak didik, apalagi yang masih berpenghasilan kurang dalam tingkat ekonomi dan kurang baik atau bisa dibilang masih lemah, hal ini dapat menjadi hambatan bagi anak-anak didik dalam mencapai prestasi belajar.

Saat ini Program Pendayagunaan ZIS di BAZNAS (Bazis) Provinsi DKI Jakarta untuk pendidikan masih berjalan seperti dahulu kala. Dimana dana zakat, infak dan sedekah yang masuk dari para donasi di salurkan kepada para mustahik sesuai dengan kebutuhannya. Program pendayagunaan tersebut adalah:

1. Bantuan Penebusan Ijazah

Bantuan ini diberikan oleh BAZNAS (Bazis) Provinsi DKI Jakarta kepada para mustahik guna meringankan beban pendidikan bagi para orang tua dikarenakan belum mampu melunasi biaya administrasi sekolah sehingga setelah masa kelulusan ijazah harus tertahan setelah melakukan perlunasan administrasi pendidikan sekolah. Biaya ini diberikan dari BAZNAS (Bazis) Provinsi DKI Jakarta, namun penyalurannya langsung disampaikan kepada sekolah bersangkutan sesuai dengan nilai pembayaran yang tercantum pada catatan biaya yang tertunggak

2. Bantuan Mahasiswa Cerdas

Bantuan ini diberikan oleh BAZNAS (Bazis) Provinsi DKI Jakarta kepada para anak bangsa yang ingin melanjutkan pendidikan ke jenjang yang lebih tinggi. Bantuan ini diberikan sepenuhnya kepada para peserta yang terpilih selama 3 tahun dalam sekali masa pengrekrutan dan hanya diberikan kepada 50 peserta yang lulus dalam seleksi. Dari seluruh peserta akan di berikan fasilitasfasilitas guna untuk mempermudah proses belajar mengajar seperti fasilitas asrama, uang makan, uang saku, uang insentif prestasi dan uang semester.

3. Bantuan Biaya Penunjang Pendidikan

Bantuan ini ditujukan kepada para murid dan mahasiswa yang kurang mampu dan keberatan dalam melaksanakan proses belajar, dimana dari mereka yang tidak terdaftar dari Kartu Jakarta Pintar (KJP) yaitu program dari Pemerintah Dearah DKI Jakarta sehingga berat dalam melaksanakan kewajiban belajar dikarenakan biaya pendidikan yang dikeluarkan tidaklah sedikit. 


\section{Bantuan Beasiswa Guru PAUD (Pendidikan Anak Usia Dini)}

Bantuan ini bertujuan agar meningkatnya tenaga pendidik PAUD yang masih tergolong jarang. Karena pada hakikatnya zakat tumbuh dan berkembang, maka disini merujuk pada nilai tersebut bahwa zakat akan dapat meningkatkan kualitas para tenaga pendidik sekaligus meningkat pula kuantitasnya kelak. Namun dalam bantuan ini akan disalurkan kepada para mahasiswa yang tergolong kurang mampu dan bersedia mengambil ketetapan nantinya sebagai guru PAUD.

5. Bantuan Santri Cerdas

Bantuan ini merupakan program dari BAZNAS (Bazis) Wilayah Jakarta Timur yang dilaksanakan pada beberapa pesantren di Jakarta. Tujuan dari adanya program ini adalah untuk meningkatkan pendidikan keagamaan khusus nya dalam mempelajari ilmu agama Islam secara utuh. Para santri yang mendapatkan bantuan ini adalah mereka yang bertekad ingin mendalami ilmu agama pada pesantren. Hal inilah yang menggugah BAZNAS (Bazis) Wilayah Jakarta Timur untuk menjalankan program bantuan santri cerdas.

Secara garis besar, bahwa pendayagunaan zakat untuk pendidikan yang dijalankan oleh BAZNAS (Bazis) Provinsi DKI Jakarta telah dinilai baik sesuai dengan standar pendayagunaan yang ada di Indonesia sesuai hasil wawancara, observasi dan dokumentasi mengenai program pendidikan yang dilakukan oleh BAZNAS (Bazis) Provinsi DKI Jakarta, dimana penyaluran dana zakat harus sesuai dengan ketetapan agama terutama dalam skala prioritas kebutuhan mustahik dengan mendahulukan orang yang tidak berdaya memenuhi kebutuhan dasar terlebih dahulu lalu memberikan bantuan pada pendidikannya, BAZNAS (Bazis) Provinsi DKI Jakarta telah menggolongkan sesuai dengan kebutuhan mustahik, bantuan diberikan sesuai dengan hasil pendapatan dan penelitian kebenaran mustahik delapan, dalam setiap tahunnya guna agar penyaluran tepat sasaran seiring berjalannya perubahan waktu. Menyalurkan bantuan sesuai dengan wilayah masing-masing dan tidak keluar dari koridor luar Provinsi DKI Jakarta. Maka melihat dari unsur ketepatan sasaran program BAZNAS (Bazis) Provinsi DKI Jakarta telah melakukannya dengan optimal dan wajar sesuai dengan hasil ketetapan yang telah 
dibuat dan telah menjaring para peserta sesuai dengan keberadaan wilayah masing-masing.Selain itu, BAZNAS (Bazis) Provinsi DKI Jakarta juga telah memiliki komite penyaluran, yang digunakan selama ini adalah penyaluran menggunakan Bank DKI, tujuannya agar dana bantuan tersebut dapat tersampaikan kepada yang berhak. Dan yang paling utama bahwa pendayagunaan harus bersifat produktif yaitu dengan adanya bantuan dariBAZNAS (Bazis) Provinsi DKI Jakarta untuk pendidikan akan banyak yang terbantu dan menjadikan lebih produktif dalam meningkatkan kualitas SDM yang akan memberikan manfaat bagi keluarga dan masyarakat sekitar.

\section{Mekanisme Pendayagunaan Dana ZIS Untuk Pendidikan Pada \\ Program Mahasiswa Cerdas}

Mekanisme yang digunakan oleh BAZNAS (Bazis) Provinsi DKI Jakarta dalam mendayagunakan dana ZIS. Sejak berdirinya BAZNAS (Bazis) Provinsi DKI Jakarta pada tahun 1968 ada banyak programprogram pendayagunaan yang telah direncanakan. Diantara program pendayagunaan zakat yang sangat berpengaruh pada peningkatan kualitas kehidupan umat yang masih terjalankan sampai saat ini di BAZNAS (Bazis) Provinsi DKI Jakarta adalah program Mahasiswa Cerdas.

Program Mahasiswa Cerdas adalah program bantuan dana pendidikan yang diperuntukkan bagi masyarakat kalangan menengah ke bawah di DKI Jakarta yang sedang menempuh pendidikan Program Sarjana (S1) dan Program Diploma (D3) di kampus negeri unggulan.

Program Mahasiswa Cerdas termasuk dalam sub dari Program Jakarta Cerdas, program ini baru di laksanakan pada tahun 2018 dengan setiap tahunnya melakukan pelaporan hasil kerja dan sudah berhasil dilaporkan pada tahun 2019. Program ini baru mulai dilaksanakan pada tahun 2018 dan akan berakhir pada tahun 2021, jadi program ini dilaksanakan dalam tiga tahun sekali di mulai dari tahun 2018 hingga masa pelaporan di tahun 2021.

Untuk mejalankan Program Mahasiswa Cerdas, BAZNAS (Bazis) Provinsi DKI Jakarta bekerja sama dengan pihak lain yaitu MAXIMA. MAXIMA adalah sebuah perusahaan yang bergerak dibidang Social Impact (organisasi yang memberikan pengaruh terhadap sosial) yaitu perusahaan yang menyediakan sumber daya manusia yang mengatur langsung, mengawas serta yang menjalankan Program Mahasiswa Cerdas, dari mulai masa pengrekrutannya hingga sampai dengan 
berakhirnya tiga tahun masa pengrekrutan Program Mahasiswa Cerdas dan selanjutnya akan dilakukan masa pengerekrutan baru untuk tiga tahun kedepan, maka BAZNAS (Bazis) Provinsi DKI Jakarta telah menjalankan sistem pendayagunaan zakat, bahwa pendayagunaan terdapat usaha-usaha nyata yang berpeluang menguntungkan, maka darisini BAZNAS (Bazis) Provinsi DKI Jakarta mendapatkan keuntungan yaitu kepercayaan dari masyarakat yang akan menjadi salah satu potensi meningkatnya jumlah muzaki dan para peserta yang lainnya adalah bahwa nantinya akan merekrut para alumni program sebagai pegawai internal BAZNAS (Bazis) Provinsi DKI Jakartasendiri dengan kapasitas yang terbaik. Sedangkan bagi perusahaan MAXIMA juga memperoleh keuntungan yaitu dengan adanya program ini, MAXIMA dapat meningkatkan program kerja serta dapat menyalurkan guru-guru tenaga pengajar yang profesional dan unggul dalam bidangnya.

Pada Program Mahasiswa Cerdas periode 2018-2021 yang pada mulanya telah mengadakan sosialisasi pada kampus-kampus PTN yang berkerjasama langsung dengan BAZNAS (Bazis) Provinsi DKI Jakarta. Kemudian mengadakan pendaftaran Program Mahasiswa Cerdas melalui jalur online di web yang telah dibuat oleh MAXIMA. Namun disini bagi para pendaftar harus mengikuti beberapa tahapan seleksi. Terdapat dua tahapan seleksi dalam Program Mahasiswa Cerdas, tahapan pertama calon peserta harus mengisi biodata diri berupa formulir, mengumpulkan Curriculume Vitae (daftar riwayat hidup), menyiapkan nilai SMA bagi calon peserta D3 dan nilai IPK terakhir bagi calon peserta S1, memperlihatkan dan menjelaskan kondisi rumah dan yang terakhir membuat dan mengumpulkan esai. Dari data yang masuk terdapat banyak peminat dari adanya Program Mahasiswa Cerdas yang berarti menunjukkan betapa banyak para anak bangsa yang antusias akan adanya program ini. Berikut adalah prosedur menjadi peserta Program Mahasiswa Cerdas.

Pada tahap pendaftaran ada 1218 peserta hal ini memberikan nilai lebih dari adanya program ini, yaitu tingginya antusias mahasiswa untuk mencoba berpartisipasi kedalamnya. Setelah masa pendaftarm selanjutnya ada proses seleksi awal, yaitu pemeriksaan berkas. Berkas yang diminta berupa berkas biodata diri dikarenakan adanya program ini adalah untuk masyarakat DKI Jakarta dalah satu pembuktian yang 
diminta adalah dengan mengumpulkan Kartu Tanda Pengenal (KTP) Jakarta. Selain itu menunjukkan Surat Keterangan Tidak Mampu (SKTM) dari kelurahan setempat yang menunjukkan bahwa peserta merupakan dari keluarga yang kurang mampu, kemudian diminta untuk mengumpulkan Curriculume Vitae (riwayat hidup) dan nilai SMA bagi calon Mahasiswa Politeknik dan nilai IPK bagi calon mahasiswa Universitas tujuannya untuk melihat seberapa banyak pengelaman dan prestasi serta kemampuan yang dimiliki. Dalam tahap ini juga diminta agar memperlihatkan kondisi rumah secara ringkas.

Gambar 1. Tahap seleksi pada Program Mahasiswa Cerdas
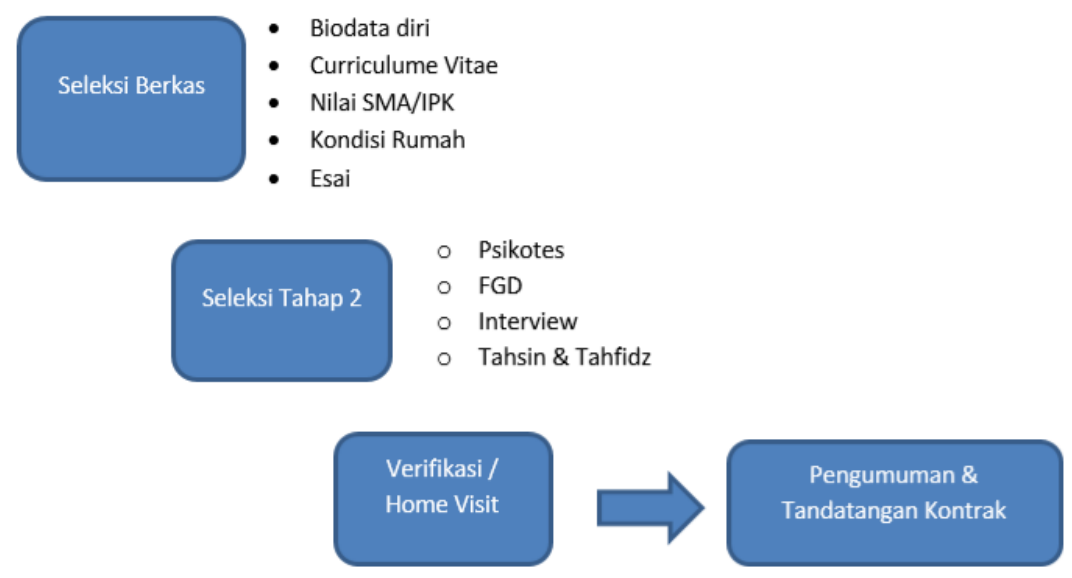

Sumber: Data sekunder di BAZNAS (Bazis) Prov. DKI Jakarta, 2018

Pada seleksi tahap selanjutnya BAZNAS (Bazis) Provinsi DKI Jakarta memberikan instruksi kepada MAXIMA untuk melakukan seleksi tahap kedua yang wajib diikuti oleh seluruh calon peserta Program Mahasiswa Cerdas yang tersisa dari seleksi sebelumnya yaitu sebanyak 163 orang. Hal ini memberikan kesempatan kepada seluruh calon peserta Program Mahasiswa Cerdas agar lebih saling mengenal sesama calon kandidat. Pada seleksi tahap kedua inilah yang akan melihat dan menilai langsung potensi yang dimiliki dari seluruh calon peserta, beberapa rentangan seleksi yang diberikan berupa:

Psikotes, pada tahap ini para kandidat akan dilihat dan dinilai langsung kapasitas dan potensi yang dimilikinya dalam menjalani Program Mahasiswa Cerdas. Psikotes dilakukan langsung oleh tim 
Psikolog Universitas Indonesia. Tujuan dari adanya psikotes adalah untuk mengetahui karakter dan kepribadian serta kesesuaian kandidat terhadap visi dan misi dari Program Mahasiswa Cerdas

FGD (Focus Group Discussion), seleksi selanjutnya berupa sesi diskusi, yang diselenggarakan dalam dua sesi; (1) Sesi pertama dilakukan menggunakan format Leaderless Group Discussion, yaitu akan dilihat dari segi kepemimpinan individual dalam menyelesaikan masalah; (2) Sesi kedua dilakukan menggunakan format diskusi kelompok terarah yang bertujuan melihat serta menilai kekompakan serta mental sosial dalam suatu kelompok. Yang akan memberikan nilai lebih dari nilai kekeluargaan dalam setiap kelompok. Tujuan umum dari FGD yaitu menilai dan melihat langsung apa yang dilakukan oleh para peserta dalam berkelompok dengan fokus observasi pada komunitas, inisiatif, problem solving, decision making dan kemampuan fasilitasi tiap-tiap peserta.

Tahsin dan Tahfidz, tahsin dan tahfidz merupakan seleksi yang paling diutamakan dari Program Mahasiswa Cerdas karena bagi kandidat yang memiliki hafalan dan sudah baik dalam membaca ayat Al-Qur`an akan dinilai lebih. Tujuan dari adanya tes tahsin yaitu untuk melihat seberapa baik pemahaman dan penguasaan peserta terhadap makhroj huruf dan tajwid dalam membaca Al-Qur'an, sedangkan tes tahfidz dilaksanakan untuk mengukur seberapa banyak hafalan AlQur'an yang dimiliki oleh para peserta. Hasil dari tes ini sangat berpengaruh untuk menentukan keberhasilan dari tiap-tiap peserta.

Interview/Wawancara, seleksi tahap akhir adalah wawancara yang dilaksanakan guna untuk memastikan kebenaran data yang telah di input peserta sebelumnya, dengan ini akan terlihat hasil nyata gambaran dari para peserta. Untuk komponen dari wawancara adalah 3K, yaitu karakter, kompetensi dan komitmen, dengan 3K akan terbukti keseriusan para peserta untuk mengikuti Program Mahasiswa Cerdas dengan segala kemampuan yang dimilikinya. Dan yang paling penting adalah interview atau wawancara dilakukan oleh orang yang ahli dan profesional dalam menentukan dan menilai dari data yang ada dengan kenyataan yang sebenarnya.

Namun, dari banyaknya calon peserta yang mengikuti seleksi berjumlah 1218 calon peserta dan melanjutkan ke proses selanjutnya hanya tersisa 348 calon peserta. Pada pengisian data terakhir termasuk 
bagian dari penglengakapan data hanya tersisa 163 pendaftar saja yang selanjutnya mereka akan mengikuti seleksi pada tahapan kedua. Berikut adalah persentase peserta Program Mahasiswa Cerdas pad BAZNAS (Bazis) Provinsi DKI Jakarta.

Gambar 2. Laporan jumlah pendaftar Program Mahasiswa Cerdas di BAZNAS (Bazis) Provinsi DKI Jakarta

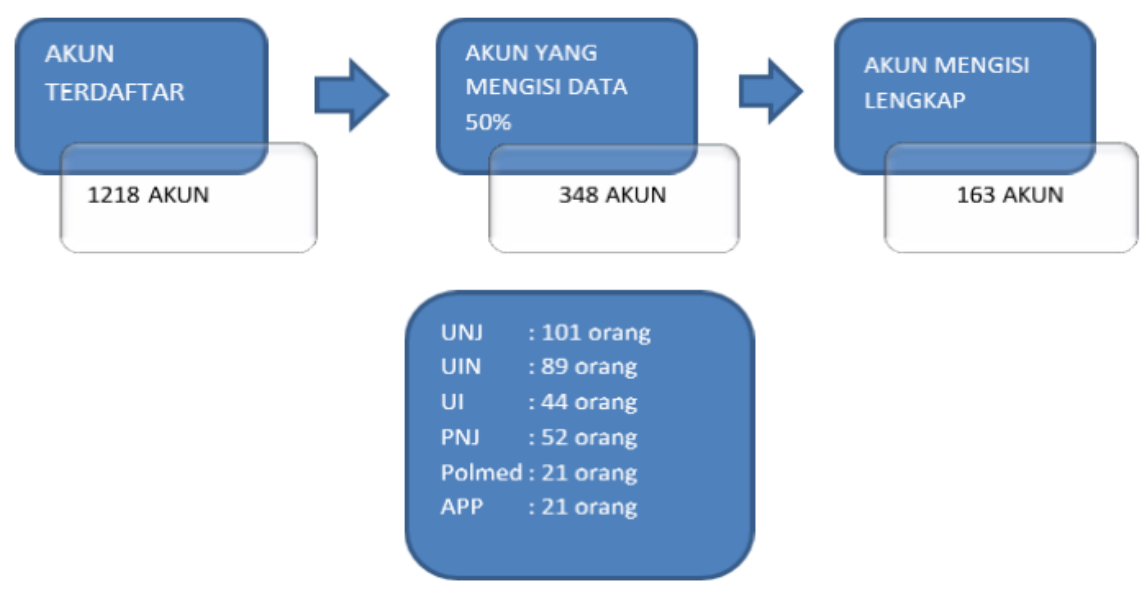

Sumber: Data sekunder di BAZNAS (Bazis) Prov. DKI Jakarta, 2018

Setelah beberapa tahapan seleksi dilaksanakan, para tim pelaksana akan melakukan proses checking akhir kepada para calon peserta atau bisa disebut juga proses verifikasi dengan mendatangi rumah hunian para calon peserta guna untuk meneliti kebenaran mustahik delapan asnaf. Karena pada dasarnya yang dapat menerima manfaat dari adanya Program Mahasiswa Cerdas adalah bagi keluarga yang tidak mampu yang mempunyai banyak kemampuam namun tidak dapat melanjutkan pendidikan ke jenjang yang lebih tinggi. Setelah dilakukan verifikasi, barulah para panitia dapat menilai serta memutuskan hasil terbaik dari seluruh calon peserta Program Mahasiswa Cerdas yang lebih layak mendapatkan manfaat pendayagunaan dana ZIS BAZNAS (Bazis) Provinsi DKI Jakarta.

Adapun langkah resmi menjadi peserta Program Mahasiswa Cerdas dibuktikan dan dinyatakan langsung berupa pengumuman yang disebar luaskan melalui website serta di setiap situs Sosial Media BAZNAS (Bazis) Provinsi DKI Jakarta maupun MAXIMA dan sekaligus memberikan seruan kepada peserta agar menghadiri 
kantorBAZNAS (Bazis) Provinsi DKI Jakarta di Jalan Awaluddin II, Tanah Abang untuk menandatangani kontrak masa pengrekrutan 3 tahun periode 2018-2021.

Dari segala yang telah diusahakan dalam pengrekrutan calon peserta Program Mahasiswa Cerdas, yaitu dengan mengadakan dua kali tahap seleksi yang begitu ketat yang dilakukan dengan menghadirkan para ahlinya langsung dengan tujuan agar mendapatkan hasil yang tepat daripada sasaran utama adanya Program Mahasiswa Cerdas ini. Jumlah awal para pendaftar keseluruhannya 1218 orang calon peserta, kemudian yang berhasil lolos menjadi peserta resmi Program Mahasiswa Cerdas untuk tiga tahun kedepan periode 2018-2021 berjumlah 50 orang peserta. Dengan rekapitulasi 40 orang peserta laki-laki dan 10 orang peserta perempuan. Berikut adalah hasil persentase sesuai jenis kelamin:

Gambar 3. Persentase jumlah persebaran peserta Program Mahasiswa Cerdas sesuai dengan jenis kelamin

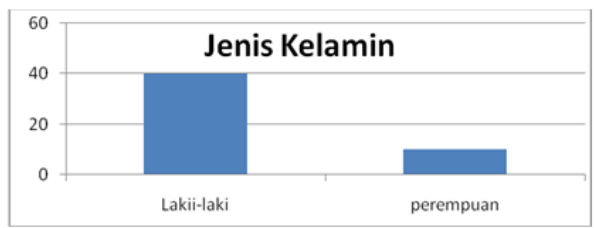

Sumber: Data sekunder di BAZNAS (Bazis) Prov. DKI Jakarta, 2019

Dari seluruh jumlah peserta yang lulus seleksi dapat dibedakan sesuai wilayahnya: Jakarta Pusat 5 orang; Jakarta Barat 9 orang; Jakarta Utara 7 orang; Jakarta Selatan 11 orang; Jakarta Timur 16 dan Kepulauan Seribu berjumlah 2 orang. Berikut adalah hasil persentase jumlah pesebaran Program Mahasiswa Cerdas sesuai domisili:

Gambar 4. Persentase jumlah persebaran peserta Program Mahasiswa Cerdas sesuai dengan domisili

\section{Domisili}

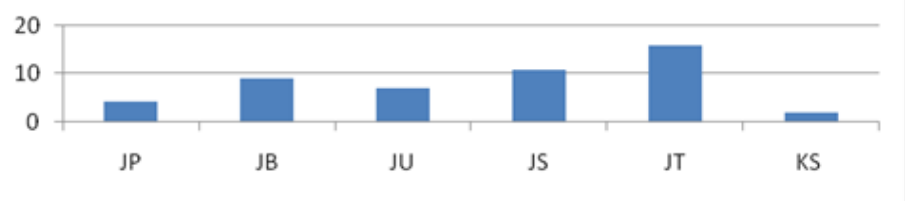

Sumber: data sekunder BAZNAS (Bazis) Prov.DKI Jakarta, 2018

PENDAYAGUNAAN DANA ZIS PADA PROGRAM MAHASISWA CERDAS BAZNAS (BAZIS) PROVINSI DKI JAKARTA 
Sedangkan persebaran para peserta Program Mahasiswa Cerdas pada setiap kampus adalah sebagai berikut: Universitas Indonesia berjumlah 8 orang; Universitas Islam Negeri Syarif Hidayatullah Jakarta berjumlah 10 orang; Universitas Negeri Jakarta berjumlah 10 orang; Politeknik Negeri Jakarta berjumlah 12 orang; Politeknik Negeri Media Kreatif berjumlah 6 orang dan Akademi Pimpinan Perusahaan berjumlah 4 orang. Berikut adalah hasil persentase jumlah Mahasiswa Cerdas sesuai kampus para peserta:

Gambar 5. Persentase jumlah persebaran peserta Program Mahasiswa Cerdas sesuai dengan kampus

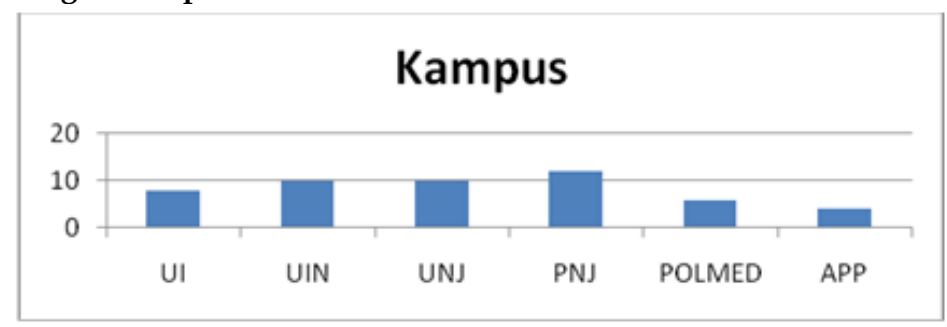

Sumber: Data sekunder di BAZNAS (Bazis) Prov. DKI Jakarta, 2018

Dalam Program Mahasiswa Cedas, BAZNAS (Bazis) Provinsi DKI Jakarta menyalurkan dana ZIS langsung kepada para peserta melalui MAXIMA yang sekaligus membina dan mengawasi para peserta di asrama. Pihak BAZNAS (Bazis) Provinsi DKI Jakartamemberikan dana ZIS kepada para peserta Program Mahasiswa Cerdas melalui MAXIMA yang nantinya akan di salurkan langsung kepada kampus-kampus sesuai biaya semesteran pertama yang dijalani para peserta. Selain itu BAZNAS (Bazis) Provinsi DKI Jakarta telah menyediakan fasilitas berupa uang saku, dan fasilitas asrama. Dari seluruh anggaran yang dikeluarkanBAZNAS (Bazis) Provinsi DKI Jakarta pada tahun 2018 lalu sesuai dengan Rencana Kerja Anggaran Rumah Tangga (RKART) sebanyak Rp. 1.290.000.000,- untuk 50 peserta Program Mahsiswa Cerdas.

Memonitor dan membina pemanfaatan ZIS yang diterima oleh mustahik. Sejauh ini BAZNAS (Bazis) Provinsi DKI Jakarta menjalankan Program Mahasiswa Cerdas dengan mengupayakan agar tetap hidupnya nilai pendidikan yang lebih tinggi ditengah masyarakat yang kurang mampu. Tujuan utama diadakannya Program Mahasiswa Cerdas adalah untuk mencetak calon pemimpin masa depan Indonesia yang berkarakter Cerdas dan siap berkolaborasi untuk umat, untuk 
memperbaiki dan meningkatkan kualitas kehidupan umat dengan menjunjung tinggi nilai pendidikan. Agar masyarakat yang kurang berdaya dalam melanjutkan pendidikan ke jenjang yang lebih tinggi dapat melanjutkan studi, dengan harapan dapat memberikan perbaikan dan kebaikan dalam keluarganya dari segi kualitas kehidupan. Berikut adalah jadwal rutinan harian pada Program Mahasiswa Cerdas, dapat dilihat tabel dibawah ini:

Tabel 1. Kegiatan harian peserta Program Mahasiswa Cerdas

\begin{tabular}{|c|c|c|c|c|c|c|c|c|}
\hline \multicolumn{9}{|c|}{ PROGRAM HARIAN } \\
\hline Jam & Senin & Selasa & Rabu & Kamis & Jumat & Sabtu & Ahad & Target \\
\hline $\begin{array}{c}03.00- \\
04.00\end{array}$ & Tahajjud & Tahajjud & Tahajjud & Tahajjud & Tahajjud & Tahajjud & & $\begin{array}{c}\text { Bertahap } \\
\text { per } \\
\text { minggu }\end{array}$ \\
\hline $\begin{array}{c}04.00- \\
05.00\end{array}$ & $\begin{array}{l}\text { Sholat } \\
\text { subuh+ } \\
\text { matsurat }+ \\
\text { kultum } \\
\text { bergilir }\end{array}$ & $\begin{array}{c}\text { Sholat subuh+ } \\
\text { matsurat+ } \\
\text { kultum } \\
\text { bergilir }\end{array}$ & $\begin{array}{c}\text { Sholat } \\
\text { subuh+ } \\
\text { matsurat }+ \\
\text { kultum } \\
\text { bergilir }\end{array}$ & $\begin{array}{c}\text { Sholat } \\
\text { subuh+ } \\
\text { matsurat }+ \\
\text { kultum } \\
\text { bergilir }\end{array}$ & $\begin{array}{l}\text { Sholat } \\
\text { subuh+ } \\
\text { matsurat+ } \\
\text { kultum } \\
\text { bergilir }\end{array}$ & $\begin{array}{l}\text { Sholat } \\
\text { subuh+ } \\
\text { matsurat }+ \\
\text { kultum } \\
\text { bergilir }\end{array}$ & & \\
\hline $\begin{array}{c}05.00- \\
06.00\end{array}$ & Tahsin & Tahfidz & $\begin{array}{l}\text { Kajian } \\
\text { Islam }\end{array}$ & Bahasa & $\begin{array}{c}\text { Tahsin dan } \\
\text { tahfidz }\end{array}$ & $\begin{array}{c}\text { Berkumpul } \\
\text { bersama } \\
\text { warga }\end{array}$ & & $\begin{array}{l}\text { Hafalan } \\
\text { min. Juz } \\
30\end{array}$ \\
\hline $\begin{array}{c}06.00- \\
07.00\end{array}$ & $\begin{array}{c}\text { Piket } \\
\text { kebersihan }\end{array}$ & $\begin{array}{c}\text { Piket } \\
\text { kebersihan }\end{array}$ & $\begin{array}{c}\text { Piket } \\
\text { kebersihan }\end{array}$ & $\begin{array}{c}\text { Piket } \\
\text { kebersihan }\end{array}$ & $\begin{array}{c}\text { Piket } \\
\text { kebersihan }\end{array}$ & $\begin{array}{c}\text { Sharing } \\
\text { Pembina }\end{array}$ & & \\
\hline $\begin{array}{l}07.00- \\
21.00 \\
\end{array}$ & \multicolumn{7}{|c|}{ Kuliah dan kegiatan mandiri } & \\
\hline $\begin{array}{l}21.00- \\
22.00\end{array}$ & \multicolumn{7}{|c|}{ Jam malam dan istirahat } & \\
\hline
\end{tabular}

Sumber: data sekunder BAZNAS (Bazis) Prov.DKI Jakarta, 2018

Selain itu terdapat beberapa program kegiatan lain yang di atur oleh BAZNAS (Bazis) Provinsi DKI Jakarta pada Program Mahasiswa Cerdas. Program tersebut terdiri dari program kegiatan harian, program pekanan, program bulanan dan program semesteran yang tujuannya untuk mengarahkan kegiatan para mahasiswa agar dapat mencapai sesuai dengan target Program Mahasiswa Cerdas. Berikut adalah tabel program yang telah dirancang:

Tabel 2. Kegiatan pekanan, bulanan dan semesteran bagi peserta Program Mahasiswa Cerdas

\begin{tabular}{|l|ll|l|l|}
\hline \multicolumn{4}{|c|}{ Program Pelaksanaan } \\
\hline No. & \multicolumn{1}{|c|}{ Nama Program } & \multicolumn{3}{c|}{ Penjelasan } \\
\hline 1. & $\begin{array}{l}\text { Diskusi pekanan dengan } \\
\text { pendamping }\end{array}$ & $\begin{array}{l}\text { Program yang bertujaun untuk memberikan } \\
\text { pandangan kepada penerima beasiswa dengan } \\
\text { mengundang senior berpengalaman dalam bidang }\end{array}$ \\
\hline
\end{tabular}


al-Mizan, Vol. 4, No.1, hlm. 54-73, Februari 2020,

P.ISSN : 2085-6792, E.ISSN : 2656-7164

\begin{tabular}{|c|c|c|}
\hline \multicolumn{3}{|c|}{ Program Pelaksanaan } \\
\hline No. & Nama Program & $\begin{array}{c}\text { Penjelasan } \\
\end{array}$ \\
\hline & & $\begin{array}{l}\text { tertentu, atau sekedar sharing evaluasi kegiatan harian } \\
\text { dengan pendamping asrama. }\end{array}$ \\
\hline 2. & Tahsin dan tahfidz & $\begin{array}{l}\text { Program perbaikan bacaan dan hafalan Al-Qur'an } \\
\text { untuk peserta }\end{array}$ \\
\hline 3. & Olahraga rutin & $\begin{array}{l}\text { Program olahraga rutin untuk menjaga kebugaran } \\
\text { peserta }\end{array}$ \\
\hline \multicolumn{3}{|r|}{ Program Bulanan } \\
\hline 1. & Training Values & $\begin{array}{l}\text { Training penanaman nilai-nilai program yaitu } \\
\text { CERDAS }\end{array}$ \\
\hline 2. & Workshop Literasi dan Kepenulisan & $\begin{array}{l}\text { Memberi pengetahuan kepada peserta terkait urgensi } \\
\text { literasi dan memberikan pelatihan kepenulisan }\end{array}$ \\
\hline 3. & BAZIS Class & $\begin{array}{l}\text { Pertemuan rutin per } 3 \text { bulan dengan BAZIS Prov, DKI } \\
\text { Jakarta dengan pemberian materi tematik sesuai } \\
\text { kesepakatan. Ajang internalisasi BAZIS dengan peserta }\end{array}$ \\
\hline 4. & Kunjungan Tokoh & $\begin{array}{l}\text { Mengunjungi tokoh publik yang bisa menjadi role- } \\
\text { model berkarakter CERDAS bagi peserta. Bertujuan } \\
\text { menumbuhkan kebanggaan terhap program dan ajang } \\
\text { berjejaring dengan tokoh }\end{array}$ \\
\hline 5. & $\begin{array}{l}\text { Training kewirausahaan dan } \\
\text { Bussiness Plan }\end{array}$ & $\begin{array}{l}\text { Memberikan pengetahuan terkait urgensi mandiri } \\
\text { finansial, dan bagaimana tips trik untuk itu. }\end{array}$ \\
\hline \multicolumn{3}{|c|}{ Program Semesteran } \\
\hline 1. & $\begin{array}{l}\text { Monitoring dan evaluasi per } \\
\text { semester }\end{array}$ & $\begin{array}{l}\text { Monitoring dan evaluasi hasil capaian dan } \\
\text { perkembangan peserta pasca } 6 \text { bulan ditempa dalam } \\
\text { program pembinaan. Kegiatan ini akan dilaksanakan } \\
\text { per asrama dengan bahan-bahan yang telah disiapkan } \\
\text { sebelumnya }\end{array}$ \\
\hline 2. & Rihlah & $\begin{array}{l}\text { Program refreshing peserta setelah } 6 \text { bulan program } \\
\text { pembinaan. Program dapat berupa jalan-jalan ke } \\
\text { tempat wisata bersama, dan lain-lain }\end{array}$ \\
\hline
\end{tabular}

Sumber: Data sekunder di BAZNAS (Bazis) Prov. DKI Jakarta, 2018

Tabel diatas adalah tentang jadwal kegiatan yang diberlakukan pada Program Mahasiswa Cerdas kepada peserta. Dalam segi pendayagunaan zakat BAZNAS (Bazis) Provinsi DKI Jakarta menjalankan ketentuan pendayagunaan zakat produktif dalam penanganan fakir-miskin dan peningkatan kualitas umat.

Banyaknya jumlah muzakki yang menyalurkan zakat, infak maupun sedekahnya melalui BAZNAS (Bazis) Provinsi DKI Jakarta merupakan sebuah keistimewaan dan sebagai tingkat kepercayaan masyarakat terhadap lembaga zakat pemerintah. Hal ini akan terus dijalakan dan akan lebih ditingkat oleh BAZNAS (Bazis) Provinsi DKI Jakarta agar menjadikan tarikan magnet kepada masyarakat luas. Harga kepercayaan inilah yang nantinya dapat membuahkan hasil lebih banyak kepada target pengumpulan zakat dan akan memberikan 
perubahan kepada kebutuhan ekonomi para mustahik agar lebih banyak mustahik yang produktif dibandingkan dalam segi konsumtif saja.

Hal ini dapat ditarik kesimpulan bahwasanya pendayagunaan dana zakat, infak dan sedekah yang dikelola oleh BAZNAS (Bazis) Provinsi DKI Jakarta sudah sangat baik dan dapat memberikan manfaat kepada masyarakat dalam segala aspek, yaitu aspek pendidikan dan sosial dalam segi produktif maupun konsumtif. Dengan terus memberikan pengendalian, pengawasan, dan pemantauan, serta melakukan pembinaan didalamnya. Setiap tahunnya BAZNAS (Bazis) Provinsi DKI Jakarta melakukan evaluasi dan melaporkan hasil dari kegiatan yang telah terjalankan.

Secara garis besar, dalam pendayagunaan zakat, infak dan sedekah yang dilakukan oleh BAZNAS (Bazis) Provinsi DKI Jakarta pada Program Jakarta Cerdas sudah baik dan optimal sesuai dengan standar pendayagunaan zakat di Indonesia. Bahwa pendayagunaan zakat dengan sistem pengelolaan yang baik yaitu mengusahakan agar para peserta program dapat memenuhi prosedur dan persyaratan yang telah disosialisasikan melalui media-media dan melalui aktifis kampus, kemudian menjalankan beberapa tahapan dalam seleksi peserta yang diutamakan dan diperhatikan adalah prioritas kebutuhan mustahik dari asnaf fisabilillah, asnaf miskin, berdomisili Jakarta, produktif dan berkomitmen agar tepat sasaran dan bersifat produktif edukatif yang mengahasilkan SDM berkualitas sebagai calon pemimpin masa depan yang berakhlak baik.

Kerja sama antara BAZNAS (Bazis) Provinsi DKI Jakarta dengan MAXIMA sebagai pengawas serta yang menjalankan Program Mahasiswa Cerdas, sudah baik dan tepat sesuai pada standar pengelolaan zakat yaitu dengan selalu melakukan perubahan kepada para peserta agar lebih produktif dalam hal pendidikan yang berfokus pada peningkatan kapasitas intelektual, emosional, manajerial, sosial dan spiritual, untuk menjaga kualitas penerima manfaat beasiswa ini dilakukan dengan metode coaching dan laporan pencapaian setiap semester. Selain itu peserta juga mendapatkan program berkala pada setiap bulannya yang akan menambah wawasan penerima manfaat. 


\section{KESIMPULAN}

1. Pendayagunaan ZIS untuk meningkatkan pendidikan di BAZNAS (Bazis) Prov. DKI Jakarta telah dilakukan dengan baik dan optimal sesuai dengan standar pendayagunaa zakat, yaitu penyaluran diberikan kepada asnaf sabilillah khusus dalam bidang keagamaan dan dhuafa-/miskin yaitu kalangan masyarakat yang kurang mampu dengan mendahulukan orang yang tidak berdaya memenuhi kebutuhan dasar terlebih dahulu lalu memberikan bantuan pada pendidikannya.

2. Mekanisme Pendayagunaan ZIS BAZNAS (Bazis) Prov. DKI Jakarta pada Program Mahasiswa Cerdas dilaksanakan dengan baik dan wajar sesuai dengan standar pendayagunaan zakat di Indonesia. Bahwa pendayagunaan zakat harus mengutamakan prioritas kebutuhan mustahik agar tepat sasaran dan bersifat produktif edukatif yang mengahasilkan SDM berkualitas sebagai calon pemimpin masa depan yang berakhlak baik. Serta pendayagunaan zakat yang dilakukan oleh BAZNAS (Bazis) Provinsi DKI Jakarta pada Program Jakarta Cerdas juga telah dilakukan sesuai wilayah masing-masing sumber zakat. BAZNAS (Bazis) Provinsi DKI Jakarta telah menggolongkan sesuai dengan kebutuhan mustahik, dengan hasil pendapatan dan penelitian kebenaran mustahik delapan, dalam setiap tahunnya guna agar penyaluran tepat sasaran seiring berjalannya perubahan waktu.

\section{DAFTAR PUSTAKA}

Bazis Provinsi DKI Jakarta \& Institut Manajemen Zakat. (2006). Manajemen ZIS Bazis Provinsi DKI Jakarta. Jakarta: Bazis Provinsi DKI Jakarta.

Departemen Agama RI. (2006). Pedoman Zakat Seri 9. Jakarta: Bagian Proyek Peningkatan Zakat dan Wakaf Jakarta.

Harahap, Sumuran. (2017). Kajian Zakat Berdasarkan Al-Qur'an. Ciputat: Gaung Persada Press Group.

Thoin, Muhammad. (2017). Pembiayaan Pendidikan Melalui Sektor Zakat. Jurnal Al-Anwal, 9(2).

Wawancara dengan Bapak Zaki Bagian Pendayagunaan BAZNAS (Bazis) Prov. DKI Jakarta, Kantor BAZNAS (Bazis) Prov. DKI Jakarta. 
Undang-Undang Nomor 23 Tahun 2011 tentang Pengelolaan Zakat, pasal 27 (Pendayagunaan Zakat).

UU No. 20 tahun 2003 tentang Sistem Pendidikan Nasional Pasal 49 ayat 1 .

https://www.nu.or.id/post/read/9067/hukum-menyalurkan-zakatuntuk-lembaga-sosial-atau-lembaga-pendidikan tentang zakat untuk pendidikan 